\title{
Volatility Interrelationship between Commodity Futures, Shanghai Stock and 10 Year Bond Indices in China
}

\author{
Mishchenko Oleg \\ Shanghai University of Finance and Economics \\ Finance Department, Guoding str. 777, Shanghai, China \\ E-mail: kontaktstar@yahoo.com
}

Received: June 12, 2011

Accepted: July 29, 2011

Published: November 1, 2011

doi:10.5539/ijef.v3n6p265

URL: http://dx.doi.org/10.5539/ ijef.v3n6p265

\begin{abstract}
This article studies the conditional means of 9 commodity futures in China from Dec, 2006 to Jan, 2010 period and finds that they are significant, which indicating that risk transfers do occur in commodity futures markets between speculators and hedgers. The paper also finds that the conditional correlation falls in period of recession; namely, when market risk rises, which is good news to asset managers since it is precisely when market volatility is high that the benefits of diversification are most appreciated. On the other hand, the negative correlation between the Government 10 year bond and commodity futures Indices rises with the bond volatility, suggesting that, unlike stocks, a bond and commodity portfolio should be tilted more towards commodity futures in periods of high bond volatility. This paper is trying to find such interrelations in Chinese commodity futures Market, Stock Market and Bond Market during 2006-2010 period, utilizing the econometrical (GARCH, ARCH) models produced by Bollerslev (1986) and Engle (1982).
\end{abstract}

Keywords: Chinese commodity futures Market, Stock Market, Bond Market, Conditional correlation, Conditional volatilities, Risk, Market volatility, Diversification, Hedging

\section{Introduction}

As the latest alternative asset class in fashion, commodity futures have recently attracted a substantial amount of interest among asset managers. There are at least four reasons for this curiosity. First, because of their low correlation with other asset classes, commodity futures are excellent portfolio diversifiers (Jensen, Johnson, and Mercer, 2000). Second, unlike stocks and bonds, commodity futures prices rise in inflationary periods, making them a good hedge against inflation (Bodie and Rosansky, 1983). Third, as only the initial margin needs to be posted when the position is open, commodity futures can be collaterized, earning substantial interests, dividends, and/or capital gains on the mandate that is not used to margin the contracts. Fourth, commodity futures present characteristics (high liquidity, complete transparency, and low transaction costs) that may make them more attractive than alternative asset classes such as hedge funds. For these reasons, commodity futures could be used to enhance traditional portfolio strategies. Jensen, Johnson, and Mercer (2002) for example show that by tactically investing in (shorting) commodity futures in periods of rising (falling) interest rates, asset managers could enhance the performance of a portfolio of unmanaged commodity futures. Similarly Vrugt, Bauer, Molenaar, and Steenkamp (2004) successfully develop a timing strategy in commodity futures markets that is based on past information. On a less positive note, commodity futures generate a return that is slightly lower than that of equities for a risk that is slightly higher and thus offer risk return characteristics that make them undesirable as stand alone investments (Edwards and Park, 1996; Jensen, Johnson, and Mercer, 2000)

Traditionally, commodity prices have been considered too volatile to play a significant role in investment strategy of any serious institutional investor. However, several studies argue that commodity prices may be an early indicator of the health of the economy because they are continually auctioned in standardized markets with efficient information (Marquis and Cunningham, 1990; Cody and Mills, 1991). Nowadays many authors share the common hypothesis that commodity prices help explain the future trajectory of macroeconomic variables, including the inflation rate. While supply and demand forces should theoretically drive commodity prices, interest rates also play an important role in determining storage costs and, therefore, total commodity supply. High interest rates increase storage costs, making it more advantageous for suppliers to sell goods on the market rather then hold them in storage. Additionally, assets such as bonds become more attractive than commodity contracts. Therefore, rising interest rates should cause commodity prices to fall (Bond 1984, Frankel 2006 and Hess 2008). 
Understanding if change in interest rate creates price volatility in commodity and stock markets is a crucial determinant of a causal nature between the two. Cointegration and vector autoregressions are useful forecasting tools but fall short of explaining causes of volatility. The GARCH model attempts to fill this void. In a typical ordinary least squares model the variance on the error term should be evenly distributed throughout the data. Many types of time series data do not have heteroskedastic errors, so allowing for heteroskedasticity did not appear necessary. However, a great deal of financial data contains heteroskedastic errors resulting from varying risks associated with differing time periods. Thus, "the expected value of the magnitude of error terms at some times is greater than at others" (Engle 2001). By analyzing heteroskedastic error terms, the GARCH model estimates causal factors in volatility. Therefore, the GARCH model has emerged as a primary tool to estimate causes of commodity price volatility. Hammoudeh and Yuan (2008) employ multiple variations of the GARCH model to examine the "characteristics of the volatility behavior of strategic [metal] commodities in the presence of positive interest rate shocks and changes in short term interest rates". They find that rising interest rates have a dulling effect on price volatility which suggests that monetary policy may be used to calm commodity markets. Besides, Hammoudeh and Yuan found that gold, and silver to some extent, are not sensitive to bad news making it a good hedge against crises, wars and high inflation - which was an extension on the earlier literature finding gold a sufficient hedge against inflation.

The principal argument for investing in commodities is that investing in assets that rise in price parallel to inflation provides a natural hedge against losses in equity and debt holdings which typically lose value during periods of unexpected inflation. Anticipated inflation, which results in high bond yields and high equity earnings growth, may result in positive real returns for stocks and bonds. But it is the unexpected inflation that should cause concern to every investor. In periods of unexpected inflation, market conditions may often lead to an increase in commodity prices, together with a weakness in stocks and bonds and thus provide a natural hedge against inflation (business cycles). (Jensen, G.R., Johnson, R.R., Mercer, J.M. (2002))

In the literature some authors differentiate between phases in the business cycle, and show that in a time of restrictive monetary policy commodities are actually able to provide portfolio return enhancement, whereas in a time of an expansive monetary policy it is more reasonable to "avoid" commodities and look for better investment alternatives. Gorton and Rouwenhorst (2005) contend that commodities and equities show different behaviors in business cycles. In the beginning of recession, stock prices usually drop but commodities prices do not drop significantly. At the end of recession, stock prices go up but commodities prices decrease.

In 2002, Jensen, Mercer, and Johnson examined the diversification benefits of adding commodity futures to a traditional portfolio that consists of US equities, foreign equities, corporate bonds, and Treasury bills from 1973 through to 1999. Consistent with previous evidence, they found that commodity futures substantially enhance portfolio performance for investors and that managed futures provide the greatest benefit. They show that the benefits of adding commodity futures accrue almost exclusively when the Federal Reserve is following a restrictive monetary policy which is a consequence of the inflationary environment. Overall, the findings indicate that investors should gauge monetary conditions to determine the optimal allocation of commodity futures within a portfolio, and whether a short or a long position should be established in a particular type of contract.

Theoretically, there are two reasons to expect why commodities should improve the risk adjusted return of the portfolio when combined with a financial-only portfolio. First, systematic positive returns should be expected from a passively constructed, long-only commodity basket on average. This is because commodity futures prices tend to be at a discount to spot prices in order to induce speculators to bear the price risk of commodity inventory holders. In other words, investors in commodity futures essentially earn a risk premium for bearing the volatile commodity price risk that inventory holders and producers wish to lay off. Thus, the positive returns from a commodity futures investment do not rely on a secular increase in spot commodity prices but rather rely on earning a risk premium over time. Second, the lack of correlation between commodities and financial assets reduces portfolio risk and hence improves the risk-adjusted return. This lack of correlation derives from each asset class' different response to inflation. Financial assets respond to inflation negatively while commodity investments respond positively. The idea is that companies and hence their stocks are more sensitive to an instability in relative prices than overall prices since relative prices determine their profits. The net result is that high commodity prices (or high input prices relative to sticky output prices) will lead to lower profits and therefore lower equity prices.

The growing use of commodities in institutional portfolios has raised the question whether commodities should be considered as a separate asset class such as stocks, bonds, international securities, real estate, etc in just starting formation Chinese market.

Insert Picture 1 Here 
Commodities, or at least commodity groups, are homogeneous in China. All tradable commodities are subjected to the standardization convention and flexibly tradable. Although commodity groups in PRC show a relatively low correlation between each other, they show an even lower or rather negative correlation to other asset classes such as stocks and bonds commodities. Over RMB 1500bn have been invested in the Chinese commodity market (until 2010) and this tendency is rapidly growing. Data concerning commodities prices, index compositions and price driving factors are openly available, its presence, deepness is developing at a high pace. Liquidity requirements to Chinese commodity, stock, bond markets are also matured enough to satisfy institutional investors.

This article contributes to the literature on commodity futures in two ways. First it studies the conditional means of 9 commodity futures in China from 2006 to 2010 and find that they are significant, indicating that risk transfers do occur in commodity futures markets between speculators and hedgers. The second contribution of this paper is with regards the conditional correlations between commodity futures and traditional asset classes in periods of high equity and bond volatility. The paper finds that the conditional correlation falls in period of recession; namely, when market risk rises. On the other hand, the correlation between the Government 10 year bond and commodity futures rises with the bond volatility, suggesting that, unlike stocks, a bond and commodity portfolio should not be tilted more towards commodity futures in periods of high bond volatility.

The remainder of the paper is organized as follows. Section 2 presents the methodology. Section 3 introduces the data. Section 4 studies the conditional means of commodity futures and the link between conditional correlations and conditional volatilities. Finally section 5 concludes.

\section{Methodology}

The decision to tilt a portfolio's optimal asset allocation towards (or away from) commodity futures depends on the means and standard deviations of the asset classes and on the correlation between the different investment vehicles. An increase in the weights allocated to commodity futures may result from the commodity futures having i) higher returns, ii) lower volatility, and / or iii) lower correlations with the Shanghai Stock Index (SSI). To analyze the factors that may influence the optimal allocation in equity and commodity futures markets, a bivariate GARCH system (by Bollerslev, Engle, and Wooldridge, 1988) that models the conditional means, variances, and covariances is used:

$$
\begin{aligned}
& R_{S, t}-R_{f, t}=\alpha_{0}+\alpha_{1} Z_{t-1}+u_{S, t} \\
& R_{F, t}=\beta_{0}+\beta_{1} Z_{t-1}+u_{F, t} \\
& h_{S, t}^{2}=c_{s}+a_{s} h_{S, t-1}^{2}+b_{s} \mathbf{u}_{S, t-1}^{2} \\
& h_{F, t}^{2}=c_{F}+a_{F} h_{F, t-1}^{2}+b_{s} \mathbf{u}_{F, t-1}^{2} \\
& h_{S F, t}=c_{S F}+a_{S F} h_{S F, t-1}+b_{S F} \mathbf{u}_{S, t-1} \mathbf{u}_{F, t-1}
\end{aligned}
$$

$R_{S, t}, R_{f, t}$, and $R_{F, t}$ are the return on the Shanghai Stock Index (SSI), the risk free rate and the return on the commodity futures respectively. (To account for the opportunity cost of investing in stocks, returns are measured in excess of the risk free rate for the Shanghai Stock Index (SSI). Due to the absence of initial investment in futures markets, raw returns are used for the commodity futures.) $Z_{t-1}$ is a $L$-vector of information variables that capture the variations through time in the prices of risk present in the equity and commodity futures markets. $\mathrm{u}_{S, t}^{2}$ and $u_{F, t}^{2}$, are the residuals on the Shanghai Stock Index (SSI) and the commodity futures, $h_{S, t}^{2}$ and $h_{F, t}^{2}$ are conditional variances, $h_{S F, t}$ is a conditional covariance. The parameters to estimate are $\alpha_{0}, \alpha_{1}, \beta_{0}$, and $\beta_{1}$ for the conditional risk premia, and $a_{i}, b_{i}$, and $c_{i}$ for $i=\{S, F\}$ for the conditional volatilities and covariances. The conditional correlations between the Shanghai Stock Index (SSI) and the commodity futures are measured as $\rho_{S F, t}=h_{S F, t} / h_{S, t} h_{F, t}$ in (1c), (1d), and (1e).

Within this framework, two hypotheses can be tested. The first test looks at the sign and significance of $\beta_{1} Z_{t-1}$, the time varying risk premia in commodity futures. This simple test will give us an idea of the applicability, or lack thereof, of the normal backwardation and contango theories in commodity futures markets. Finding that $\beta_{1} Z_{t-1}$ is positive will lend support to the normal backwardation theory (Keynes, 1930; Miffre, 2000) and will suggest that a long position in commodity futures is optimal. In this case, the futures price rises over the life of the contract to entice speculators to take long positions. Speculators indeed require a positive risk premium to compensate them for the price risk short hedgers are not able to transfer to long hedgers at no cost. Finding however that $\beta_{1} Z_{t^{-}}$is negative will lend support to the contango theory (Hicks, 1939) and will suggest that a short position in commodity futures is optimal. In this case, the futures price falls as maturity approaches to compensate net short speculators for taking on the risk of price fluctuation long hedgers are unable to transfer to short hedgers at no cost. Finally finding that there is no risk premium in commodity futures markets $\left(\beta_{1} Z_{t-1}=0\right)$ will lend support to the unbiased hypothesis. In this case, the futures price does not change as maturity approaches as hedgers transfer their risks to one another at 
no cost and thus are not willing to pay a risk premium to speculators.

The second test focuses on the relation between conditional correlations and conditional volatilities by simply regressing the former on the latter two as follows:

$$
\rho=\alpha+\beta_{S} h_{S, t}+\beta_{F} h_{F, t}+e_{t}
$$

A finding that $\beta_{S}$ is positive will suggest that the conditional correlation rises with the volatility of the equity market and thus that the evidence from international stock markets can be extrapolated to the equity and commodity futures markets. A finding that $\beta_{S}$ is negative however will suggest that commodity futures behave in a way similar to bonds (Hunter and Simon, 2004) and thus could be considered as a useful tool for portfolio diversification in periods of recession.

To study the conditional correlation between commodity futures and bond prices, we modify equations (1a), (1c), and (1e) and (2) and replace them with the following equations (subscript B denotes bond):

$$
\begin{aligned}
& R_{B, t}-R_{f, t}=\alpha_{0}+\alpha_{1} Z_{t-1}+u_{B, t} \\
& h_{B, t}^{2}=c_{B}+a_{B} h_{B, t-1}^{2}+b_{B} \mathbf{u}^{2}{ }_{B, t-1} \\
& h_{B F, t}=c_{B F}+a_{B F} h_{B F, t-1}+b_{B F} \mathbf{u}_{B, t-1} \mathbf{u}_{F, t-1} \\
& \rho_{B F, t}=\alpha+\beta_{B} h_{B, t}+\beta_{F} h_{F, t}+e_{t}
\end{aligned}
$$

\section{Data}

The data comprises prices on the Shanghai Stock Index (SSI), a China 10 year government bond index, and 9 China commodity futures contracts, among which - 6 agricultural commodities (corn, cotton, oats, soybean meal, soybean oil, soybeans, sugar), 2 metal commodities (copper and aluminum) and 1 energy commodity (heating oil). The dataset spans the period Dec, 2006 to Jan, 2010. To avoid weekend, thin trading, and expiration effects, the closing prices on the nearest maturity futures contract are used.

Table 1 presents summary statistics for the Shanghai Stock Index (SSI) excess return, the bond excess return and the commodity futures return. Figure 1 plots the average annualized returns against the average annualized standard deviations. Since the risk return relationship in commodity futures markets does not conform to the CAPM (Bodie and Rosansky, 1983), it is not surprising to see that assets with higher volatilities do not necessarily offer higher returns. For example, the futures contracts on copper and aluminum have both negative average returns and relatively high standard deviations. Computing the reward to risk ratios confirms that commodity futures are by and large poor stand-alone investments: Only sugar offers a close risk adjusted return to the Shanghai Stock Index (SSI) over the period considered. Corn, oats, and T-bond exhibit the worse performance.

\section{Insert Table 1 Here}

\section{Empirical Results}

\subsection{Relationship between Commodity Futures and the Shanghai Stock Index (SSI)}

Table 2 reports coefficient estimates for the mean equations and results of the normal backwardation tests. In spite of insignificant estimates on the lagged information variables, the results overwhelmingly support the hypothesis that the risk premia are significant and thus that risk transfers do occur in commodity futures markets. Contango is supported for 2 commodity futures which present negative and significant risk premia. Normal backwardation is supported for 1 commodity futures for which the risk premium is both positive and significant. Support for the hypothesis that the futures price is an unbiased estimate of the maturity spot price is weak (cotton, corn, sugar, soybeans). The size of the commodity futures risk premia is of interest too. The annualized risk premium in contango markets equals $39.2 \%$ on average. The annualized risk premium in markets with normal backwardation equals $36.3 \%$. So it appears that the risk premia are significant both in statistical and economic terms, and follows approximately similar return prospective (which can ne explained by closely regulated commodity futures system in China).

\section{Insert Table 2 Here}

Consistent with risk aversion, consumption smoothing, and asset pricing models, the market risk premium is positive and significant for all commodity futures (left hand side of Table 2). The average size of the equity risk premium is highly exceeded of $5.00 \%$. Robust inferences on the relation between conditional correlation and volatilities can only be drawn within a well-specified model. To ensure that this condition is met, Table 3 reports the parameter estimates from the GARCH models. It is clear from this table that, irrespective of the commodity futures under consideration, the GARCH specification does capture the variation through time in the Shanghai Stock Index (SSI) variances, the futures variances, and the covariance between the Shanghai Stock Index (SSI) and the 
commodity futures. Note that the sum of the parameter estimates $a_{S}$ and $b_{S}$ is close to unity, as is the sum of $a_{f,}$ and $b$ ${ }_{f}$ suggesting strong persistence in variance. The covariance GARCH parameters $\mathrm{S}_{\mathrm{F}}$ a and $\mathrm{S}_{\mathrm{F}}$, which account for the conditional covariance between the Shanghai Stock Index (SSI) and futures returns, are positive and significant.

\section{Insert Table 3 Here}

With our well specified model at hand, we can now study the conditional correlation and volatilities and the impact that the latter may have on the former. The results are reported in Table 4. By and large, conditional volatilities tend to be of the same magnitude as their unconditional counterparts (in Table 1). Without any exceptions, commodity futures in China exhibit smaller conditional risk than the Shanghai Stock Index (SSI), only heating oil has almost approached it (which can be explained by dependence of China on oil import and worlds oil market price). The correlation between the volatilities of the Shanghai Stock Index (SSI) and commodity futures is low (11.4 0\% on average). That is, when the market experiences turbulence, commodities encounter less turmoil. The conditional reward to volatility ratios, measured as the annualized conditional mean (in Table 2) to the annualized conditional volatility (in Table 4), range from 0.63 for sugar to 0.4 for corn, with an average of 0.07 , suggesting that many commodity futures should be bought.

\section{Insert Table 4 Here}

Let us now turn our attention to another risk measure - conditional correlation. The results are in the right hand side of Table 4. The conditional correlations with the Shanghai Stock Index (SSI) reported in Table 4 are relatively high, with an average of 0.045 and a range of -2.7 (copper) to 3.28 (soybeans). Second, the conditional correlations are volatile too, with standard deviations ranging from $13.6 \%$ for copper to $24.5 \%$ for cotton. Third, regressions of the conditional correlations on a time trend reveal a fall in the conditional correlations over time. The t-statistics on the time trend is negative and significant for most of the commodities. This indicates that the segmentation between the Shanghai Stock Index (SSI) and the commodity futures markets is increasing over time. Summarizing the evidence thus far, while the conditional means of commodity futures is often times positive, the conditional volatilities in futures markets are larger than that of the Shanghai Stock Index (SSI). This suggests that the risk return trade off is worse than we once thought and that a long position in commodity futures is often times optimal. The conditional correlations between the Shanghai Stock Index (SSI) and commodity futures are small, mildly volatile, and decrease over time.

The paper also focuses on the following issue: Do the conditional correlations between commodity futures and the market rise in periods of market turbulence? The results are reported in Table 5 . The evidence strongly suggests that there is a significant relation between correlation and market risk. Approximately two thirds of the coefficients on $\beta_{\mathrm{S}}$ in (2) are significantly negative at the 5\% level. For most of our commodity futures, the conditional correlation falls in period of recession; namely, when market risk rises. This is good news to long investors in commodity futures: It is precisely when market volatility is high that the benefits of diversification are most appreciated.

\section{Insert Table 5 Here}

Across the 9 futures, the average $\beta_{S}$ coefficient in equation (2) is $2.5 \%$. This suggests that market risk has also an economic impact on conditional correlations. Namely, a $1 \%$ rise in market risk leads on average to a $2.5 \%$ rise in correlation. This ultimately indicates that the more volatile the market is, the more dynamic the optimal asset allocation of a hedge fund manager should be. Investors, by allocating higher portfolio weights to commodity futures during turbulent periods (different signs: 2.55264 and -4.00487), can benefit from the decrease in correlation and the enhanced risk reduction that ensues. The $\beta_{S}$ coefficients are particularly low for Soybean meal (-6.7) and Soybean Oil (-5.03). This indicates that these commodity futures are the best candidates for portfolio diversification in periods of recession. In the case of Soybean meal, its low $\beta_{S}$ is accompanied by a negative conditional correlation with and a comparative volatility to, the market, therefore enhancing its diversification properties even further and living up to its reputation as a good hedge in times of market stress. Note however that the explanatory power of the model is low for some of the commodities and the constant is often statistically significant, suggesting that the conditional volatilities may not be the only drivers of conditional correlations.

\subsection{Relationship between Commodity Futures and 10 year government bond}

Mostly positive $\beta_{S}$ coefficient above suggests that commodity futures are not similar to bonds (negatively correlated). As such, we shall replicate part of our earlier study with the 10 year government bond, and examine its dynamics with commodity futures. Once again, the bivariate GARCH is well specified with coefficients within expectations. Table 6 presents the average of the conditional risk premium in commodity futures when government bonds are used as the alternative asset class (on the left hand side), along with results of the relationship between the conditional correlation and conditional volatilities (on the right hand side). On the contrary to the Shanghai Stock Index (SSI), 
here contango is supported for a majority of futures contracts. Equally to the market, $\beta_{B}$ in (4) is positive on the whole (6.7). That is, when bond volatility increases, the correlation between the bond and commodity futures rises (if we exclude soya bean oil). $100 \%$ of all commodity futures exhibit positive $\beta_{B}$ coefficients. Due to its negative association with the 10 year government bond, commodity futures, in general, would not increase the benefits of diversification in periods of high interest rate volatility.

Insert Table 6 Here

With soybean oil, soybean meal and corn displaying the strongest co-movement with the 10 year government bond in this category copper (4.3), sugar (5.06), and heating oil (-2.99) seem better candidates for inclusion in a 10 year government bond portfolio in periods of high interest rate volatility. Stating it differently soybean oil, soybean meal and corn are best candidates for inclusion in a 10 year government bond portfolio in periods of high interest rate volatility once short sale of bonds will be introduced in China.

\section{Conclusion}

Commodity futures are considered as excellent portfolio diversifiers and an effective hedge against inflation. Still little is known of their conditional reward to risk ratios and of the way they co-vary with other asset classes over the business cycle. To fill in the gap, the estimation with the bivariate GARCH model has done and the following conclusions were drawn.

First, it is found that the conditional means of commodity futures are significant, indicating, in line with Keynes (1930) and Hicks (1939), that risk transfers do occur in commodity futures markets between speculators and hedgers. The risk premium claimed by speculators for undertaking the risk hedgers want to get rid off is negative (positive) for almost half commodity futures, suggesting that a short (long) position in these commodities in Chinese market could enhance traditional portfolio strategies. Second, we find that the conditional correlation between commodity futures and the Shanghai Stock Index (SSI) rises in period of recession; namely, when market risk rises. This is good news to short asset managers since it is precisely when market volatility is high that the benefits of diversification are most appreciated. On the other hand, the negative correlation between the Treasury bond and commodity futures rises with the bond volatility, suggesting that, unlike stocks, a bond and commodity portfolio should not be tilted more towards commodity futures in periods of high bond volatility.

Bringing all the evidence together it appears that soya bean meal and heating oil futures have positive risk premia and decreasing correlations with the Shanghai Stock Index (SSI) in periods of high market volatility. As such they are the best candidates for inclusion in a well diversified portfolio of stocks and bonds. Other commodity futures offer positive risk premia but their higher correlations with traditional asset classes in periods of high volatility make them less welcomed as portfolio diversifiers. Finally, short positions should be taken in 4 commodities (corn, cotton, soya bean oil, soya beans).

\section{References}

Bodie, Z. (1983). Commodity futures as a hedge against inflation. Journal of Portfolio Management. (Spring). (pp. 12-17). http://dx.doi.org/10.3905/jpm.9.3.12

Bollerslev, T., Engle, R. F. \& Wooldridge, J. M. (1988). A capital asset pricing model with time-varying covariances. Journal of Political Economy. (96). (pp. 116-131). http://dx.doi.org/10.1086/261527

Fama, E. \& French, K. (2002). The equity premium. Journal of Finance. (pp. 637-659). http://dx.doi.org/10.1111/1540-6261.00437

Gorton, G. \& Rouwenhorst, K. (2004) Facts and fantasies about commodity futures. Yale ICF working paper. (no. 04-20).

Cambridge, H. \& Simon, D. (2004). Benefits of international bond diversification. Journal of Fixed Income. (13). (pp. 57-72).

Jensen, G., Johnson, R. \& Mercer, J. (2002). Tactical asset allocation and commodity futures. Journal of Portfolio Management. (Summer). (pp. 100-111). http://dx.doi.org/10.3905/jpm.2002.319859

Miffre, J. (2000). Normal backwardation is normal. Journal of Futures Markets. (20, 9). (pp. 803-821).

Vrugt, E.B., Bauer, R., Molenaar, R. \& Steenkamp, T. (2004). Dynamic commodity timing strategies. Working paper. Maastricht University.

Hammoudeh, Shawkat \& Yuan Yuan. (2008). Metal Volatility in the Presence of Oil and Interest Rate Shocks. Energy Economics. (30). (pp. 606-620). http://dx.doi.org/10.1016/j.eneco.2007.09.004

Hess, D. (2008). How do Commodity Futures Respond to Macroeconomic news? Financial Market Portfolio 
Management. (22). (pp. 127-146).

Lunieski, C. ( 2009). Commodity Price Volatility and Monetary Policy Uncertainty: A GARCH Estimation. Issues in Political Economy. (Vol 19) (pp. 108-124).

Nijman, T. \& Swinkels, L. (2003). Strategic and tactical allocation to commodities for retirement savings schemes. Discussion Paper (20). Tilburg University.

Table 1. Descriptive statistics: Commodity futures, Shanghai Stock Index(SSI), Government Bond

\begin{tabular}{|l|c|c|}
\hline & Means & Std Dev \\
\hline Copper & $-26.41 \%$ & $31.03 \%$ \\
\hline Alum & $-8.13 \%$ & $29.56 \%$ \\
\hline Corn & $12.93 \%$ & $21.82 \%$ \\
\hline Sugar & $19.01 \%$ & $41.22 \%$ \\
\hline Cotton & $14.46 \%$ & $26.73 \%$ \\
\hline Soybeans & $17.28 \%$ & $22.83 \%$ \\
\hline Soybean meal & $20.79 \%$ & $35.90 \%$ \\
\hline Soybean Oil & $7.49 \%$ & $36.30 \%$ \\
\hline Heating Oil & $27.90 \%$ & $48.92 \%$ \\
\hline 000300. SH Stock Index & $28.36 \%$ & $52.74 \%$ \\
\hline $10-$ year Bonds Index & $5.02 \%$ & $2.18 \%$ \\
\hline
\end{tabular}

The information variables, $Z_{t-1}$ follow from Fama and French (1989) and Chen (1991), and are employed as predictors of business cycle one period ahead. These include the first lag in the Shanghai Stock Index (SSI) dividend yield, default spread, and the term structure of interest rates. To capture any momentum or reversal in equity, bond, and futures returns, two additional information variables are considered: the first lag in the Shanghai Stock Index (SSI) or bond returns is used as an information variable in (1a) or (3a) and the first lag in the commodity futures returns is used as a predictor in (1b). 
Table 2. Test of normal backwardation

\begin{tabular}{|c|c|c|c|c|c|c|}
\hline \multicolumn{7}{|c|}{ Market equation (coefficients) } \\
\hline & Intercept & Rs,t-1 & DYt-1 & DSt-1 & TSt-s & Annualized mean \\
\hline Copper & -0.00742 & 0.86818 & -0.01775 & 0.25046 & 0.41882 & 0.07689 \\
\hline Alum & -0.00247 & 0.28572 & -0.02131 & 0.13890 & 0.11728 & -0.13863 \\
\hline Corn & 0.00015 & 0.20268 & -0.02653 & 0.24436 & -0.01175 & 0.08392 \\
\hline Sugar & -0.00550 & 0.50218 & 0.08267 & 0.14060 & 0.11779 & 0.14002 \\
\hline Cotton & -0.00237 & 0.24005 & -0.03305 & 0.43357 & 0.11851 & 0.10972 \\
\hline Soybeans & 0.00454 & 0.12240 & -0.11566 & 0.26525 & -0.07441 & 0.11643 \\
\hline Soybean meal & 0.00116 & 0.11769 & -0.02982 & -0.19375 & 0.09959 & 0.19268 \\
\hline Soybean Oil & 0.00085 & 0.13616 & -0.10699 & 0.31987 & 0.11290 & 0.04212 \\
\hline Heating Oil & -0.00351 & 0.41121 & -0.07592 & 0.06186 & 0.42647 & 0.19451 \\
\hline
\end{tabular}

\begin{tabular}{|c|c|c|c|c|c|c|}
\hline & T-stat & & & & & \\
\hline & Intercept & Rs,t-1 & DYt-1 & DSt-1 & TSt-s & Annualized mean \\
\hline Copper & -1.23474 & 21.09972 & -0.14865 & 0.34026 & 1.24941 & 0.10777 \\
\hline Alum & -0.98384 & 16.59872 & -0.42656 & 0.45106 & 0.83634 & -0.50701 \\
\hline Corn & 0.07252 & 14.62755 & -0.65987 & 0.98581 & -0.10411 & 0.39580 \\
\hline Sugar & -1.45202 & 19.35434 & 1.09809 & 0.30290 & 0.55722 & 0.32190 \\
\hline Cotton & -1.23344 & 18.27933 & -0.86733 & 1.84550 & 1.10767 & 0.50732 \\
\hline Soybeans & 1.82781 & 7.20381 & -2.34600 & 0.87269 & -0.53760 & 0.49639 \\
\hline Soybean meal & 0.32337 & 4.80567 & -0.41965 & -0.44224 & 0.49916 & 0.58417 \\
\hline Soybean Oil & 0.21886 & 5.11774 & -1.38591 & 0.67208 & 0.52088 & 0.11713 \\
\hline Heating Oil & -1.04544 & 17.91090 & -1.13962 & 0.15061 & 2.28009 & 0.51686 \\
\hline
\end{tabular}

\begin{tabular}{|c|c|c|c|c|c|c|}
\hline \multicolumn{7}{|c|}{ Futures equation (coefficients) } \\
\hline & Intercept & Rf,t-1 & DYt-1 & DSt-1 & TSt-s & Annualized mean \\
\hline Copper & -0.00478 & 0.00002 & -0.07906 & -0.05765 & 0.46470 & -0.26229 \\
\hline Alum & -0.00660 & -0.00010 & 0.04278 & -0.24088 & 0.38721 & -0.08141 \\
\hline Corn & -0.00121 & 0.00000 & -0.01521 & 0.19420 & 0.09263 & 0.12566 \\
\hline Sugar & -0.01293 & 0.00000 & 0.17439 & -0.49729 & 0.63363 & 0.18863 \\
\hline Cotton & -0.00638 & -0.00003 & 0.03134 & 0.04146 & 0.37552 & 0.14494 \\
\hline Soybeans & 0.00258 & 0.00000 & -0.09060 & 0.15884 & 0.05094 & 0.17175 \\
\hline Soybean meal & 0.00072 & 0.00003 & -0.03523 & -0.21775 & 0.16394 & 0.21063 \\
\hline Soybean Oil & -0.00156 & 0.00429 & -0.08174 & 0.17297 & 0.27174 & 0.07561 \\
\hline Heating Oil & -0.00689 & -0.00876 & -0.02005 & -0.16948 & 0.63381 & 0.27996 \\
\hline
\end{tabular}

\begin{tabular}{|c|c|c|c|c|c|c|}
\hline \multicolumn{7}{|c|}{ T-stat } \\
\hline & Intercept & $\mathbf{R f} \mathrm{t}_{\mathrm{t}-1}$ & DY $_{t-1}$ & $\mathbf{D S}_{\mathrm{t}-1}$ & $\mathbf{T S}_{\mathrm{t}-\mathrm{s}}$ & Annualized mean \\
\hline Copper & -1.41196 & 0.45667 & -1.17131 & -0.13830 & 2.46220 & -0.84467 \\
\hline Alum & -2.03167 & -0.08027 & 0.66123 & -0.60272 & 2.14040 & -0.27514 \\
\hline Corn & -0.50283 & 0.02108 & -0.31797 & 0.65724 & 0.69240 & 0.57559 \\
\hline Sugar & -2.86773 & 0.01174 & 1.94153 & -0.89656 & 2.52305 & 0.45731 \\
\hline Cotton & -2.17886 & -0.36622 & 0.53732 & 0.11509 & 2.30252 & 0.54188 \\
\hline Soybeans & 1.02858 & 0.03628 & -1.81508 & 0.51527 & 0.36497 & 0.75165 \\
\hline Soybean meal & 0.18166 & 0.12792 & -0.44757 & -0.44802 & 0.74505 & 0.58636 \\
\hline Soybean Oil & -0.39198 & 1.34020 & -1.02881 & 0.35311 & 1.22477 & 0.20812 \\
\hline Heating Oil & -1.28248 & -1.37420 & -0.18767 & -0.25728 & 2.11653 & 0.57179 \\
\hline
\end{tabular}

Returns are jointly modeled as:

$Z_{t-1}$ is a $\mathrm{L}$ - vector of information variables (first lag in the Shanghai Stock Index (SSI) / futures returns $\left(R_{S_{t-1}} / R_{F t-1}\right)$, dividend yield (DY $\left.{ }_{t-1}\right)$, default spread $\left(D S_{t-1}\right)$, and the term structure of interest rates $\left(T S_{t-1}\right)$ that capture the variations through time in the prices of risk present in the equity and commodity futures markets. $u_{S, t}$, and $u_{F t}$, are the residuals on the Shanghai Stock Index (SSI) and the commodity futures. 
Table 3. Specification of the conditional covariance matrix with the Shanghai Stock Index (SSI)

\begin{tabular}{|l|r|r|r|r|r|r|r|r|r|}
\hline $\begin{array}{l}\text { Futures } \\
\text { contracts }\end{array}$ & \multicolumn{1}{l|}{ Csindex } & \multicolumn{1}{l}{ Csf } & \multicolumn{1}{l}{ Cf } & \multicolumn{1}{l}{ As } & \multicolumn{1}{l}{ Asf } & \multicolumn{1}{l}{ Af } & \multicolumn{1}{l}{ Bs } & \multicolumn{1}{l}{ Bsf } & \multicolumn{1}{l}{ Bf } \\
\hline Copper & 0.00003 & -0.00009 & 0.00004 & 0.08454 & -0.05234 & 1.05278 & -0.14449 & 0.54646 & -1.07052 \\
\hline Alum & 0.00000 & -0.00004 & 0.00000 & 0.03622 & -0.39201 & 0.87668 & -0.04966 & 0.25159 & -0.88270 \\
\hline Corn & -0.00001 & -0.00008 & 0.00000 & 0.04941 & -0.18503 & 0.45277 & -0.06706 & 0.70688 & -0.45462 \\
\hline Sugar & 0.00001 & -0.00004 & 0.00000 & 0.04525 & -0.24377 & 0.99386 & -0.07273 & 0.19330 & -1.00973 \\
\hline Cotton & 0.00001 & -0.00001 & 0.00000 & 0.05559 & -0.10943 & 0.99307 & -0.08927 & 0.11929 & -1.00594 \\
\hline Soybeans & 0.00000 & -0.00020 & -0.00001 & 0.34193 & -0.34452 & 1.12204 & -0.37312 & 1.38725 & -1.12721 \\
\hline Soy meal & -0.00001 & 0.00015 & -0.00001 & 0.32605 & -0.26069 & 0.81836 & -0.34058 & -0.43961 & -0.81935 \\
\hline Soy oil & 0.00000 & -0.00007 & 0.00000 & 0.13745 & -0.32350 & 0.41794 & -0.14541 & 0.21441 & -0.42258 \\
\hline Heat oil & 0.00000 & -0.00007 & 0.00000 & 0.06240 & -0.17529 & 0.89696 & -0.09718 & 0.26244 & -0.90756 \\
\hline
\end{tabular}

\begin{tabular}{|c|c|c|c|c|c|c|c|c|c|}
\hline & \multicolumn{9}{|c|}{ T-stat } \\
\hline $\begin{array}{l}\text { Futures } \\
\text { contracts }\end{array}$ & $\mathrm{C}_{\text {s }}$ index & $\mathrm{C}_{\mathrm{sf}}$ & $\mathbf{C}_{\mathrm{f}}$ & $\mathbf{A}_{\mathrm{s}}$ & $\mathbf{A}_{\text {sf }}$ & $\mathbf{A}_{\mathbf{f}}$ & Bs & $\mathbf{B}_{\mathrm{sf}}$ & $\mathbf{B}_{\mathrm{f}}$ \\
\hline Copper & 0.01440 & -0.05073 & 0.04563 & 1.38442 & -1.16263 & 3.98435 & -1.80210 & 0.21139 & -4.01510 \\
\hline Alum & -0.00063 & -0.11559 & -0.00172 & 0.51310 & -10.34626 & 2.06171 & -0.58566 & 2.09741 & -2.06865 \\
\hline Corn & -0.01039 & -0.21874 & -0.00404 & 0.62798 & -4.15384 & 0.93081 & -0.73608 & 2.14200 & -0.93477 \\
\hline Sugar & 0.01130 & -0.07107 & -0.00291 & 0.70146 & -5.82820 & 3.15344 & -0.88806 & 2.49803 & -3.17842 \\
\hline Cotton & 0.01201 & -0.04924 & 0.00358 & 0.84121 & -2.72664 & 3.07661 & -1.08400 & 1.33443 & -3.09842 \\
\hline Soybeans & -0.00815 & -0.52280 & -0.01379 & 2.56001 & -9.19386 & 3.49096 & -2.67397 & 1.83414 & -3.49783 \\
\hline Soy meal & -0.00650 & 0.28611 & -0.01643 & 1.62300 & -6.63393 & 1.68657 & -1.66238 & -1.47750 & -1.68788 \\
\hline Soy oil & -0.00100 & -0.12304 & -0.00448 & 0.74338 & -8.53628 & 1.08715 & -0.76869 & 0.55057 & -1.09457 \\
\hline Heat oil & 0.00287 & -0.11392 & 0.00045 & 0.93203 & -3.59934 & 2.74352 & -1.16929 & 2.20559 & -2.76326 \\
\hline
\end{tabular}

Returns and (co)variances are jointly modeled as:

$Z_{t-1}$ is a $\mathrm{L}-$ vector of information variables. $u_{S, t}$, and $u_{F, t}$, are the residuals on the Shanghai Stock Index (SSI) and the commodity futures, Squired $h_{S, t}$ and Squired $h_{F, t}$ are conditional variances, $h_{S F, t}$, is a conditional covariance. The parameters to estimate are $\alpha_{0}, \alpha_{1}, \beta_{0}$, and $\beta_{1}$ for the conditional risk premia, and $a_{i}, b_{i}$, and $c_{i}$ for $i=\{S, F\}$ for the conditional volatilities and covariances. The conditional correlations between the Shanghai Stock Index (SSI) and the commodity futures are measured as $\rho_{S F, t}=h_{S F, t} /\left(h_{S, t} h_{F, t}\right)$

Table 4. Summary statistics of conditional volatility and correlation

\begin{tabular}{|l|c|c|c|c|c|c|}
\hline & \multicolumn{3}{|c|}{ Conditional Volatility } & \multicolumn{2}{c|}{ Conditional Correlation } \\
\hline & $\begin{array}{c}\text { Annualized } \\
\text { Mean }\end{array}$ & $\begin{array}{c}\text { Annualized } \\
\text { Volatility }\end{array}$ & $\begin{array}{c}\text { Correlation } \\
\text { with } \\
\text { Sh Index } \\
\text { Volatility }\end{array}$ & $\begin{array}{c}\text { Conditional } \\
\text { reward } \\
\text { to risk ratio }\end{array}$ & Average \\
Deviation \\
\hline Shanghai Stock Index & 0.28297 & 0.27861 & & 1.01564 & & \\
\hline Copper & -0.26229 & 0.09643 & 0.23516 & -2.72015 & 0.01781 & 1.36325 \\
\hline Alum & -0.08141 & 0.08754 & 0.61362 & -0.92991 & -0.02734 & 1.66522 \\
\hline Corn & 0.12566 & 0.04766 & 0.40995 & 2.63648 & 0.13358 & 2.27903 \\
\hline Sugar & 0.18863 & 0.17013 & 0.63157 & 1.10871 & 0.06857 & 1.57751 \\
\hline Cotton & 0.14494 & 0.07155 & 0.60471 & 2.02586 & 0.04001 & 2.44839 \\
\hline Soybeans & 0.17175 & 0.05221 & 0.20508 & 3.28953 & 0.03275 & 1.65959 \\
\hline Soy meal & 0.21063 & 0.12904 & 0.22677 & 1.63232 & 0.02348 & 1.86072 \\
\hline Soy Oil & 0.07561 & 0.13198 & 0.27357 & 0.57287 & 0.06070 & 2.37668 \\
\hline Heating Oil & 0.27996 & 0.23973 & 0.48660 & 1.16783 & 0.06019 & 1.66282 \\
\hline Average: & 0.09483 & 0.11403 & 0.40967 & 0.97595 & 0.04553 & 1.87702 \\
\hline
\end{tabular}


Table 5. Conditional correlation and conditional market volatility

\begin{tabular}{|l|c|c|c|c|c|}
\hline & \multicolumn{2}{|c|}{ Market Volatility } & \multicolumn{2}{c|}{ Futures Volatility } & \multirow{2}{*}{ R-sq } \\
\hline & Estimate & T-ratio & Estimate & T-ratio & 0.00039 \\
\hline Copper & -0.13221 & -0.10361 & -1.23942 & -0.42253 & 0.00394 \\
\hline Corn & 11.27952 & 1.44547 & -11.36541 & -1.57756 & 0.00104 \\
\hline Sugar & 6.44830 & 0.63686 & -7.97363 & -0.81017 & 0.00068 \\
\hline Cotton & 1.67277 & 0.38220 & -2.78170 & -0.60279 & 0.00140 \\
\hline Soybeans & 13.41511 & 0.75724 & -13.15281 & -0.91844 & 0.00064 \\
\hline Soybean meal & 1.39187 & 0.20699 & -3.82556 & -0.55347 & 0.00253 \\
\hline Soybean Oil & -6.70281 & -1.21094 & 3.51160 & 0.69009 & 0.00130 \\
\hline Heating Oil & -5.03482 & -0.83533 & 2.14788 & 0.36004 & 0.00040 \\
\hline Average: & 0.63602 & 0.15932 & -1.36476 & -0.44435 & 0.00137 \\
\hline
\end{tabular}

The results are derived by running the regression:

$\rho_{S F, t}=\alpha+\beta_{S} h_{S, t}+\beta_{F} h_{F, t}+e_{t}$

Table 6. Conditional correlation and conditional bond volatility

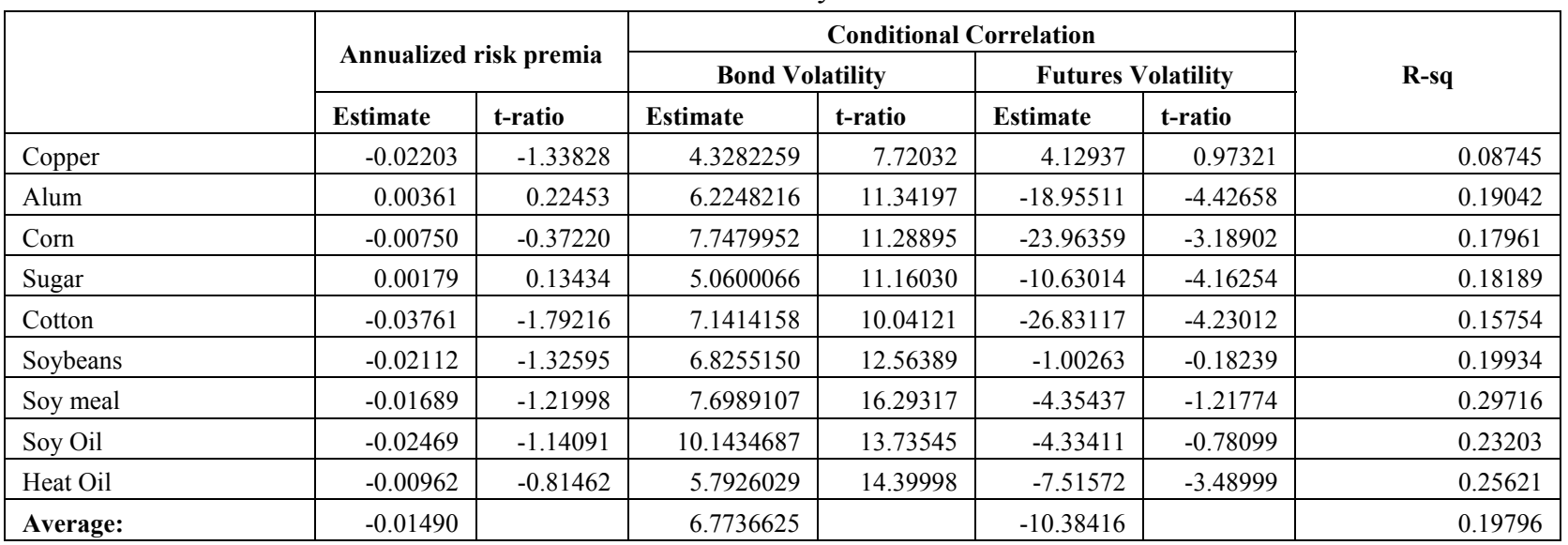

The results are derived by running the regression:

$\rho_{B F, t}=\alpha+\beta_{B} h_{B, t}+\beta_{F} h_{F, t}+e_{t}$

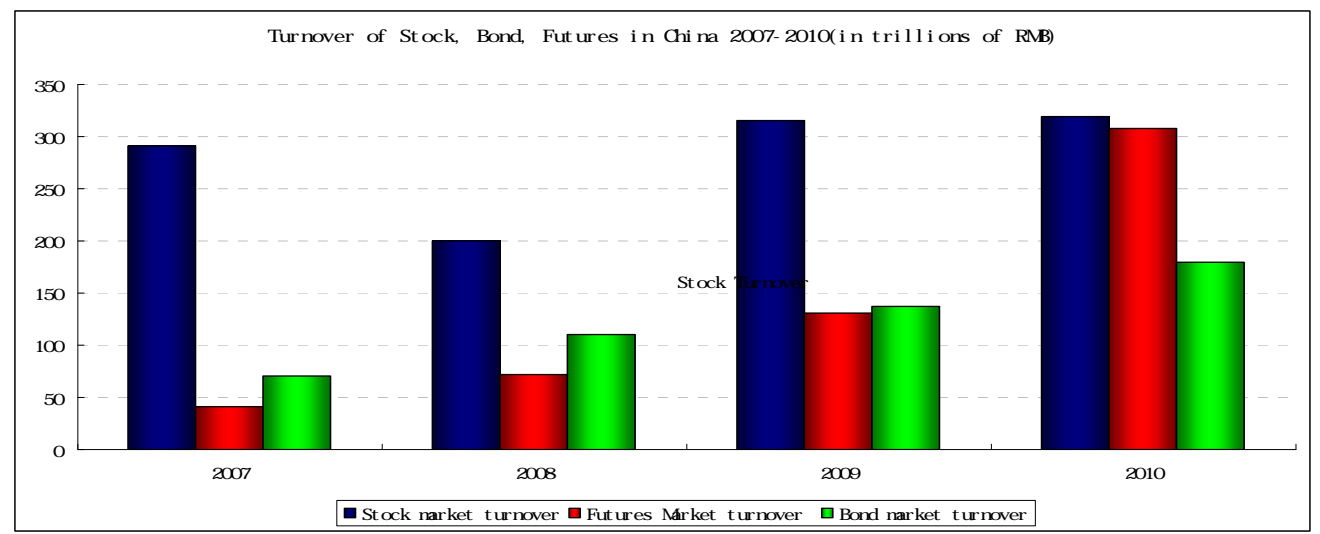

Picture 1. Comparative Turnover of Stock, Bond, Futures in China 2007-2010 (in trillions of RMB) 